\title{
Viral RNA in Blood as Indicator of Severe Outcome in Middle East Respiratory Syndrome Coronavirus Infection
}

\author{
So Yeon Kim, Sun jae Park, Sook Young Cho, \\ Ran-hui Cha, Hyeon-Gun Jee, Gayeon Kim, \\ Hyoung-Shik Shin, Yeonjae Kim, Yu Mi Jung, \\ Jeong-Sun Yang, Sung Soon Kim, Sung Im Cho, \\ Man Jin Kim, Jee-Soo Lee, Seung Jun Lee, \\ Soo Hyun Seo, Sung Sup Park, Moon-Woo Seong
}

We evaluated the diagnostic and clinical usefulness of blood specimens to detect Middle East respiratory syndrome coronavirus infection in 21 patients from the 2015 outbreak in South Korea. Viral RNA was detected in blood from $33 \%$ of patients at initial diagnosis, and the detection preceded a worse clinical course.

$\mathrm{M}$ iddle East respiratory syndrome coronavirus (MERS$\mathrm{CoV}$ ) is a zoonotic, betacoronavirus lineage C RNA virus that was first identified in Saudi Arabia in 2012 (1). MERS-CoV causes respiratory and renal illness in humans, and infection often progresses to severe pneumonia, acute respiratory distress syndrome, renal failure, or death in a subset of patients (2). Risk factors, including patient age, preexisting health conditions, and high viral load in upper respiratory specimens, have been suggested to be related to disease severity and death $(3,4)$. However, pathogenesis and clinical characteristics promoting recovery from infection or progression to serious organ failure have not been well elucidated.

Respiratory specimens are preferred for viral RNA detection and confirmatory diagnosis of MERS-CoV infection in humans (5). MERS-CoV has broad tissue tropism, including the kidney, intestinal tract, liver, histiocytes, macrophages, and T lymphocytes, but viral RNA has been found inconsistently in blood, urine, and fecal specimens (6-10). Reports have described small numbers of cases with extrapulmonary virus; therefore, it remains unclear whether extrapulmonary specimens have any diagnostic usefulness in determining infection or whether extrapulmonary viral detection has clinical implications in disease management.

Author affiliations: National Medical Center, Seoul, South Korea (S.Y. Kim, S.j. Park, S.Y. Cho, R.-h. Cha, H.-G. Jee, G. Kim, H.-S. Shin, Y. Kim, Y.M. Jung); Korea Centers for Disease Control and Prevention, Cheongju-si, South Korea (J.-S. Yang, S.S. Kim); Seoul National University College of Medicine, Seoul (S.I. Cho, M.J. Kim, J.-S. Lee, S.J. Lee, S.H. Seo, S.S. Park, M.-W. Seong)

DOI: http://dx.doi.org/10.3201/eid2210.160218
A large MERS-CoV outbreak occurred in 2015 in South Korea. This outbreak comprised the first imported case and subsequent infection of 185 patients (11). Our study aimed to evaluate the diagnostic utility of blood specimens for MERS-CoV infection by using large numbers of patients with a single viral origin and to determine the relationship between blood viral detection and clinical characteristics.

\section{The Study}

We collected 21 pairs of EDTA whole blood and serum specimens from 21 patients with MERS-CoV after admission to the National Medical Center in Seoul, South Korea. MERS-CoV infection initially was diagnosed by the Korea Centers for Disease Control and Prevention using respiratory specimens (11). After admission, each patient was reassessed for epidemiologic information and clinically managed with monitoring.

Specimens were stored at $-80^{\circ} \mathrm{C}$ before analyses. Viral RNA was extracted and eluted with a MagNA Pure LC 2.0 automated nucleic acid extractor and MagNA Pure LC total nucleic acid isolation kit (both from Roche Diagnostics, Mannheim, Germany) according to the manufacturer's instructions. Specimen volumes were $100 \mu \mathrm{L}$ EDTA whole blood and $200 \mu \mathrm{L}$ serum, and elution volumes were $100 \mu \mathrm{L}$ for EDTA whole blood and $50 \mu \mathrm{L}$ for serum. One-step, real-time reverse transcription PCR (rRTPCR) was performed for the 3 MERS-CoV gene regions (upstream envelope [upE], open reading frame [ORF] 1a, and nucleocapsid) with an AgPath-ID One-Step RT-PCR kit (Applied Biosystems, Foster City, CA, USA) and an ABI7500 real-time PCR system (Applied Biosystems). Human ribonuclease (RNase) $\mathrm{P}$ was amplified in parallel for sample quality control $(5,12,13)$. In each test, the viral RNA was considered detected when amplification before cutoff was observed from at least 2 different targets in MERS-CoV with pass of sample quality control. The robustness of rRT-PCR was demonstrated for qualitative concordance of positivity or negativity by using different types of specimens (online Technical Appendix Table 1, http://wwwnc.cdc.gov/EID/article/22/10/16-0218Techapp1.pdf). We calculated the viral copy concentration in the blood using standard curves constructed from the cycle threshold $\left(\mathrm{C}_{t}\right)$ of serially diluted $10^{5}$ copies $/ \mu \mathrm{L}$ of upE RNA (provided by the University of Bonn Medical Center, Bonn, Germany). 
The results of the blood viral RNA analyses did not affect clinical management. We assessed the relationships among clinical and molecular diagnostic factors with the IBM SPSS Statistics program 22.0 (SPSS Inc., Chicago, IL, USA). In each test, $\mathrm{p}<0.05$ was considered statistically significant. The institutional review board of the National Medical Center approved this study (H-1508-057-002).

We assessed patient demographics, their clinical features, and disease outcomes (Tables 1, 2; online Technical Appendix Table 2). The time difference was an average of 1.5 days (median 1 , range $0-5$ days) between when the initial diagnostic respiratory specimens and blood specimens were obtained. At admission, viral RNA was detected in 6 $(29 \%)$ of 21 EDTA whole blood and $6(29 \%)$ of 21 serum samples from infected patients. Two patients showed viral positivity in either specimen subtype of EDTA whole blood or serum; therefore, the overall detection rate for MERS-CoV was 33\% (7/21) in blood. The concordance rate of viral assay was $90 \%$ (19/21) between EDTA whole blood and serum specimens. Blood virus concentration was 3,130 copies/mL EDTA whole blood (range 2,080-17,400 copies $/ \mathrm{mL}$ ), equivalent to a median upE $\mathrm{C}_{t}$ of 37.55 , and 1,300 copies/mL serum (range 490-10,200 copies/mL, median upE $\mathrm{C}_{\mathrm{t}}$ 36.88).

Blood viral RNA positivity at admission was associated with fever $\geq 37.5^{\circ} \mathrm{C}$ on the sampling date $(\mathrm{p}=0.007)$, requirement for mechanical ventilation during the following clinical course $(p=0.003)$ and extracorporeal membrane oxygenation $(\mathrm{p}=0.025)$, and patient death $(\mathrm{p}=$ 0.025 , all by 2 -tailed Fisher exact test; Figure). Blood viral RNA positivity was not associated with viral $\mathrm{C}_{t}$ in the initial diagnostic lower respiratory specimens, or requirement of oxygen supplementation during the following clinical course. Between the blood viral RNA-positive and -negative groups, we found no differences in age, duration from symptom onset to diagnosis of MERS-CoV infection, or
Table 1. Demographic characteristics of 21 Middle East respiratory syndrome coronavirus-infected patients, South Korea, 2015

\begin{tabular}{lc}
\hline Characteristic & Value \\
\hline No. & 21 \\
\hline Median age, y (range) & $64(23-86)$ \\
\hline $\begin{array}{l}\text { Sex, no. } \\
\text { M }\end{array}$ & 9 \\
$\quad \mathrm{~F}$ & 12 \\
\hline Median hospitalization, d (range) & $17(2-138)$ \\
\hline Death rate, \% & 23.8 \\
\hline Median no. days exposed to virus (range) & $3(1-20)$ \\
\hline $\begin{array}{l}\text { Median duration between symptom onset } \\
\text { and initial diagnosis, d (range) }\end{array}$ & $2(0-12) \dagger$ \\
\hline $\begin{array}{l}\text { *Based on contact history. } \\
\text { †Two asymptomatic patients were excluded from analysis. }\end{array}$
\end{tabular}

an invasive procedure before the specimens were obtained (online Technical Appendix Table 3).

Viral loads in the lower respiratory specimens at the initial confirmatory diagnosis showed no effect on patient survival (Figure). Patient death was not associated with length of time from symptom onset to diagnosis of MERSCoV infection (online Technical Appendix Table 3).

Our results showed that the detection rate of blood viral RNA was low in the early phase of infection in patients with a confirmed diagnosis, similar to results from a previous study (14). These findings contrasted with those of severe acute respiratory syndrome coronavirus infection (15). Therefore, in the case of MERS-CoV infection, blood does not have the highest diagnostic yield for the initial confirmatory diagnosis. The viral load in blood was low, even in detected cases. A proportion of MERS-CoV isolates in the 2015 Korea outbreak harbored a $\mathrm{C} \rightarrow \mathrm{T}$ substitution in the third nucleotide of the ORF1a primer binding site (GenBank accession nos. KT374052-374055). This mismatch may partially contribute to the insensitivity of ORF1a assay observed in this study. An alternative sensitive target replacing ORF1a might be useful in studies using blood specimens.

Table 2. Differences in Middle East respiratory syndrome coronavirus detection by rRT-PCR among specimen types, South Korea, $2015^{*}$

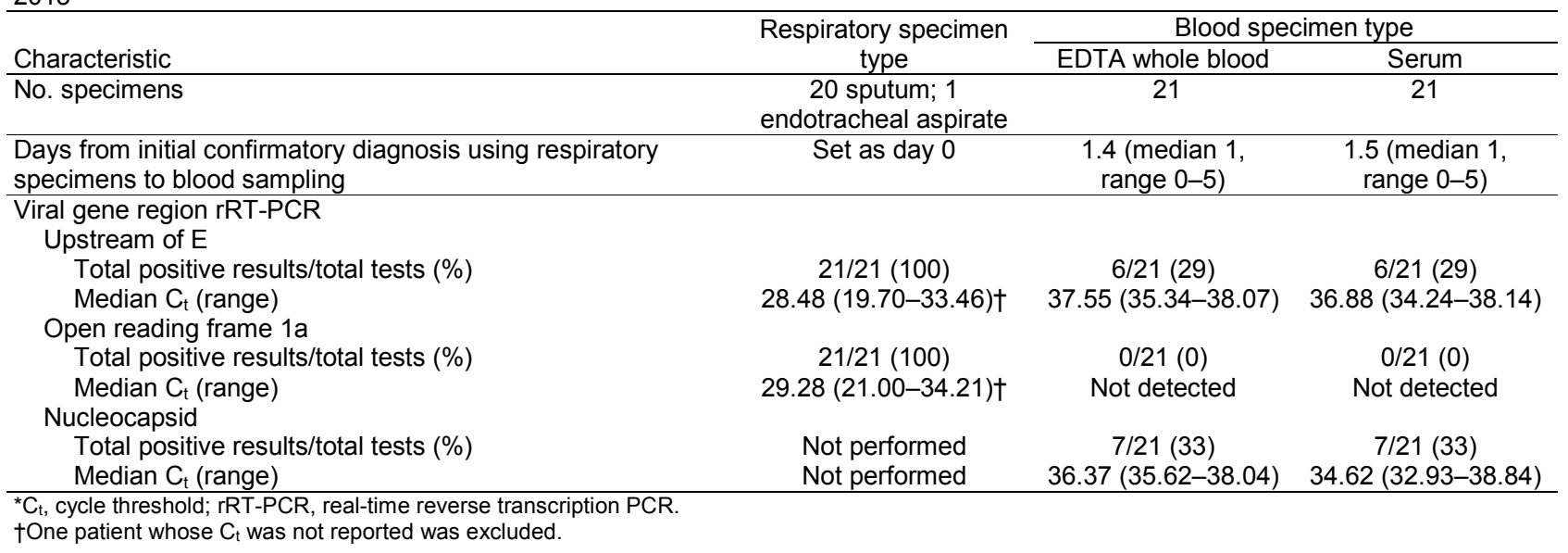



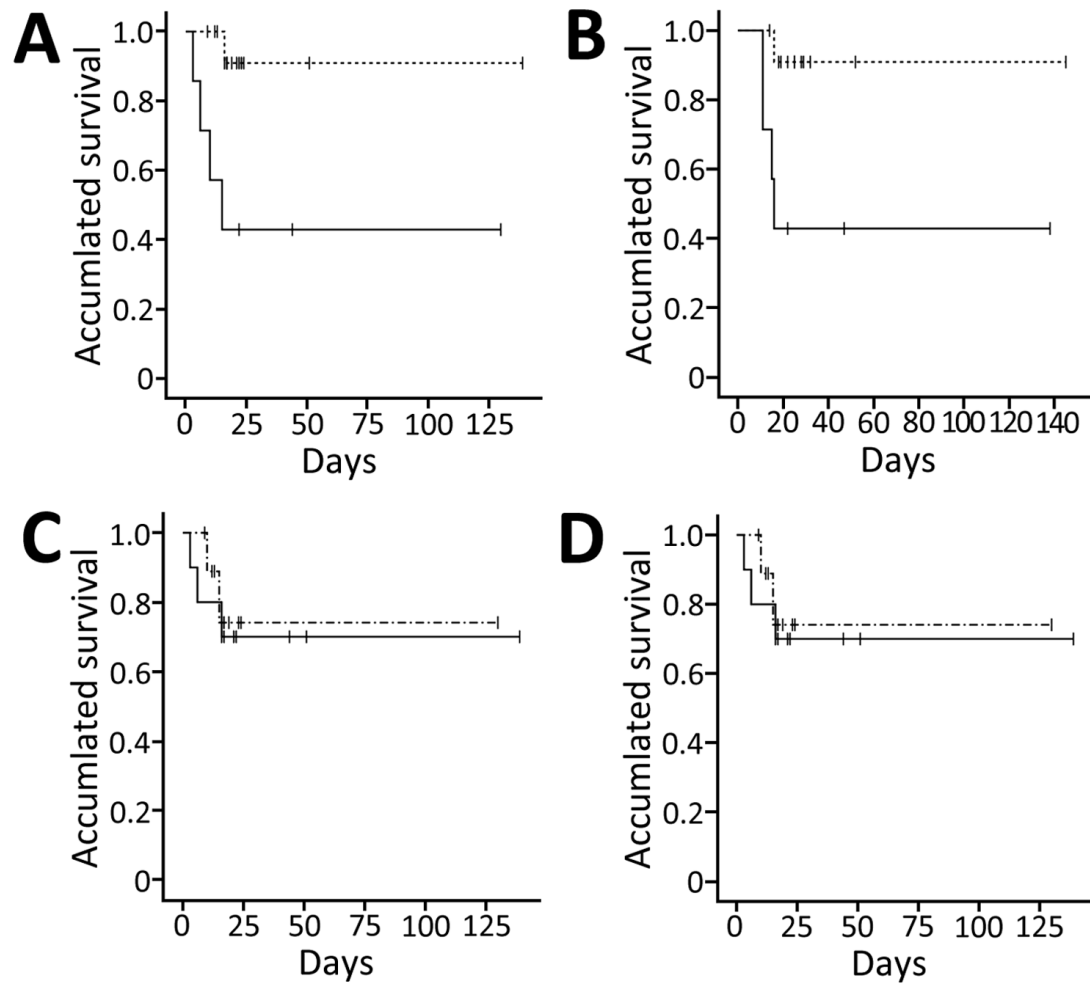

Figure. Differences in survival among Middle East respiratory syndrome coronavirus-infected patients, South Korea, 2015. A, B) Survival difference between the blood viral RNA-positive (solid line) and -negative (broken line) groups. Survival was defined as the time from initial confirmatory diagnosis to death before hospital discharge (A) (Kaplan-Meier survival analysis, log rank $p=0.009$; Breslow $p$ $=0.006)$ and as the time from symptom onset to death (B) (Kaplan-Meier survival analysis, $\log$ rank $p=0.017$; Breslow $p=$ 0.015). C, D) Survival difference between the high respiratory viral load (solid line) and low respiratory viral load (broken line) groups. Viral loads were classified into 2 groups: patients who harbored viral loads above the median load of patients and patients who harbored below. Survival was defined as time from initial confirmatory diagnosis to death. Cycle threshold $\left(C_{t}\right)$ values were calculated for real-time reverse transcription PCRs targeting the upstream of envelope region $(C)$ and open reading frame 1a region (D) (Kaplan-Meier survival analysis, log rank $p=0.739$; Breslow $p=$ 0.630). Tick marks along data lines indicate data-censored time points.
Blood viral RNA has been detected in a few case reports of MERS-CoV fatalities (8-10). Our data of 42 specimens from cross-sectional time points focusing on early viremia showed that blood viral RNA was present in a subpopulation of patients and that these patients had significantly poorer prognoses, as demonstrated by the need for more frequent mechanical ventilation and the increased risk for death. Further large studies using serial daily specimens that are collected throughout the admission period-, both upper and lower respiratory specimens and paired measurement of viral RNA and antibody in blood - might help overcome the limitation of the current study, which included relatively small numbers of deceased patients $(24 \%[5 / 21])$.

\section{Conclusions}

Our data showed a detection rate of 33\% for viral RNA in blood at initial diagnosis, which was insufficient for initial confirmatory diagnosis. Blood viral RNA at the early phase was related to a worse clinical course in infected patients and might be a good prognostic indicator of severe outcome. Measuring blood viral RNA at hospital admission might be useful.

\section{Acknowledgments}

We thank Christian Drosten for providing the in vitro transcribed RNAs of MERS-CoV genes.
This research was supported by a research program funded by the National Medical Center Research Institute, grant number NMC-2015-MS-02.

Dr. Kim is a medical doctor at the Department of Laboratory Medicine of National Medical Center in South Korea. Her research interests include molecular diagnostics and infectious diseases.

\section{References}

1. Zaki AM, van Boheemen S, Bestebroer TM, Osterhaus AD, Fouchier RA. Isolation of a novel coronavirus from a man with pneumonia in Saudi Arabia. N Engl J Med. 2012;367:1814-20. http://dx.doi.org/10.1056/NEJMoa1211721

2. Zumla A, Hui DS, Perlman S. Middle East respiratory syndrome. Lancet. 2015;386:995-1007. http://dx.doi.org/10.1016/S01406736(15)60454-8

3. Majumder MS, Kluberg SA, Mekaru SR, Brownstein JS. Mortality risk factors for Middle East respiratory syndrome outbreak, South Korea, 2015. Emerg Infect Dis. 2015;21:2088-90. http://dx.doi.org/10.3201/eid2111.151231

4. Feikin DR, Alraddadi B, Qutub M, Shabouni O, Curns A, Oboho IK, et al. Association of higher MERS-CoV virus load with severe disease and death, Saudi Arabia, 2014. Emerg Infect Dis. 2015;21:2029-35. http://dx.doi.org/10.3201/eid2111.150764

5. World Health Organization. Laboratory testing for Middle East respiratory syndrome coronavirus. Interim guidance (revised) [cited 2015 Oct 15]. http://apps.who.int/iris/bitstream/10665/176982/1/ WHO MERS LAB 15.1 eng.pdf

6. Chan JF, Chan KH, Choi GK, To KK, Tse H, Cai JP, et al. Differential cell line susceptibility to the emerging novel human 
betacoronavirus 2c EMC/2012: implications for disease pathogenesis and clinical manifestation. J Infect Dis. 2013;207:1743-52. http://dx.doi.org/10.1093/infdis/jit123

7. Chu H, Zhou J, Wong BH, Li C, Chan JF, Cheng ZS, et al. Middle East respiratory syndrome coronavirus efficiently infects human primary $\mathrm{T}$ lymphocytes and activates the extrinsic and intrinsic apoptosis pathways. J Infect Dis. 2016;213:904-14. http://dx.doi.org/10.1093/infdis/jiv380

8. Guery B, Poissy J, el Mansouf L, Séjourné C, Ettahar N, Lemaire X, et al.; MERS-CoV study group. Clinical features and viral diagnosis of two cases of infection with Middle East respiratory syndrome coronavirus: a report of nosocomial transmission. Lancet. 2013;381:2265-72. http://dx.doi.org/10.1016/ S0140-6736(13)60982-4

9. Drosten C, Seilmaier M, Corman VM, Hartmann W, Scheible G, Sack S, et al. Clinical features and virological analysis of a case of Middle East respiratory syndrome coronavirus infection. Lancet Infect Dis. 2013;13:745-51. http://dx.doi.org/10.1016/ S1473-3099(13)70154-3

10. Poissy J, Goffard A, Parmentier-Decrucq E, Favory R, Kauv M, Kipnis E, et al.; MERS-CoV Biology Group. Kinetics and pattern of viral excretion in biological specimens of two MERS-CoV cases. J Clin Virol. 2014;61:275-8. Erratum in: J Clin Virol. 2015,63:94. http://dx.doi.org/10.1016/j.jcv.2014.07.002

11. Korea Centers for Disease Control and Prevention. Middle East respiratory syndrome coronavirus outbreak in the Republic of
Korea, 2015. Osong Public Health Res Perspect. 2015; 6:269-78. Erratum in: Osong Public Health Res Perspect. 2016. http://dx.doi.org/10.1016/j.phrp.2015.08.006

12. Corman VM, Eckerle I, Bleicker T, Zaki A, Landt O,

Eschbach-Bludau M, et al. Detection of a novel human coronavirus by real-time reverse-transcription polymerase chain reaction. Euro Surveill. 2012;17:20285.

13. Lu X, Whitaker B, Sakthivel SK, Kamili S, Rose LE, Lowe L, et al. Real-time reverse transcription-PCR assay panel for Middle East respiratory syndrome coronavirus. J Clin Microbiol. 2014;52:67-

75. http://dx.doi.org/10.1128/JCM.02533-13

14. Corman VM, Albarrak AM, Omrani AS, Albarrak MM, Farah ME, Almasri M, et al. Viral shedding and antibody response in 37 patients with Middle East respiratory syndrome coronavirus infection. Clin Infect Dis. 2016;62:477-83.

15. Ng EK, Hui DS, Chan KC, Hung EC, Chiu RW, Lee N, et al. Quantitative analysis and prognostic implication of SARS coronavirus RNA in the plasma and serum of patients with severe acute respiratory syndrome. Clin Chem. 2003;49:1976-80. http://dx.doi.org/10.1373/clinchem.2003.024125

Address for correspondence: Moon-Woo Seong, Department of Laboratory Medicine, Seoul National University Hospital, Seoul National University College of Medicine, 101, Daehak-ro, Jongno-gu, Seoul 110-744, South Korea; email: mwseong@snu.ac.kr

\section{The Public Health Image Library (PHIL)}
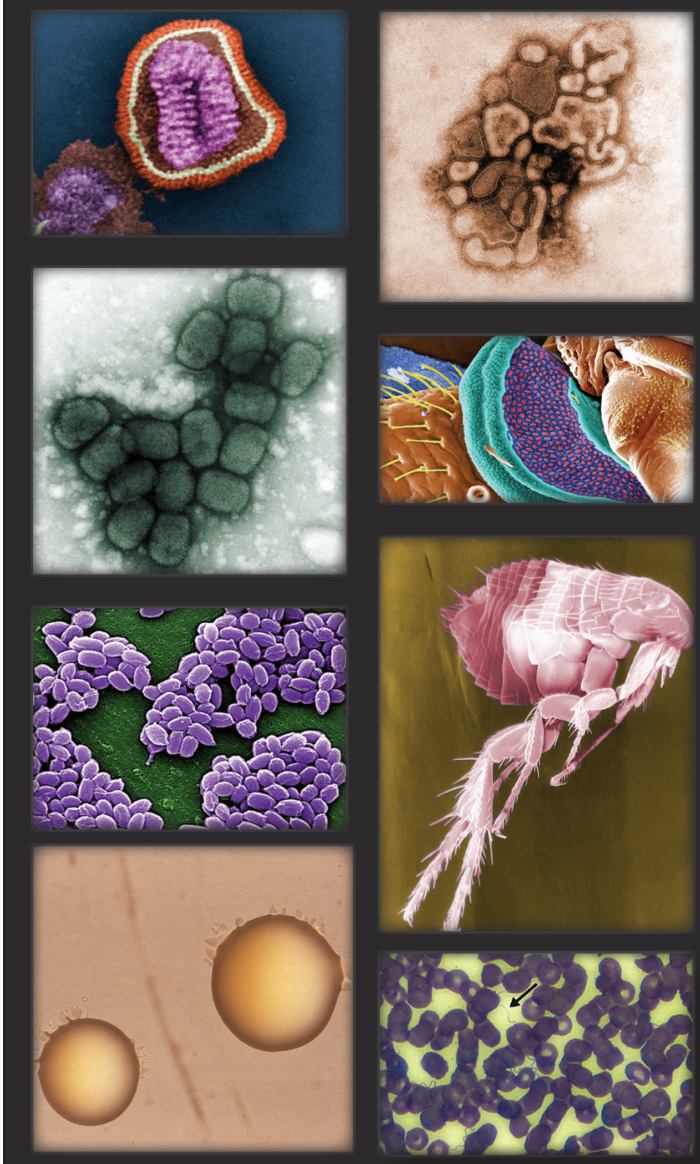

The Public Health Image Library (PHIL), Centers for Disease Control and Prevention, contains thousands of public health-related images, including high-resolution (print quality) photographs, illustrations, and videos.

PHIL collections illustrate current events and articles, supply visual content for health promotion brochures, document the effects of disease, and enhance instructional media.

PHIL images, accessible to PC and Macintosh users, are in the public domain and available without charge.

\section{Visit PHIL at: http: / / phil.cdc.gov/phil}

